\title{
DIRASAH
}

Volume 3, Number 2, Agustus 2020

p-ISSN: 2615-0212 | e-ISSN: 2621-2838

https://ejournal.iaifa.ac.id/index.php/dirasah

\begin{tabular}{|c|c|c|}
\hline Accepted: & Revised: & Published: \\
April 2020 & Mei 2020 & Agustus 2020 \\
\hline
\end{tabular}

\section{Temperance dan Perceived Organizational Support Sebagai Prediktor Perilaku Organizational Citizenship Behaviorpada Guru}

\author{
Amin Al Adib ${ }^{1}$, Erita YDS $^{2}$, dan Nina Situmorang ${ }^{3}$ \\ Universitas Ahmad Dahlan Yogyakarta \\ e-mail: '1adibdotcom@gmail.com, ${ }^{2}$ erita@gmail.com,dan \\ 3ninasitumorang@gmail.com
}

\begin{abstract}
The purpose of this research is to (1) find out whether temperance and perceived organizational support can predict organizational citizenship behavior; (2) whether temperance can predict organizational behavior; and (3) whether perceived organizational support can predict organizational citizenship behavior. A quantitative method is used in this research. Subjects used in this research are High School teachers around the LP Ma'arif Wonosobo area. The number of individuals within the population is 170, with 52 individuals as samples. The samples were chosen through purposive sampling. Data for this study was collected by using the temperance scale, perceived organizational support scale, and OCB scale. Data analysis used is multiple regression with the help of IBM SPSS. Results of this study shows that (1)temperance and perceived organizational support can predict organizational citizenship behavior with an $R$ scale score of 0.418; (2)temperance can predict organizational behavior; and (3)perceived organizational support can predict organizational citizenship behavior.
\end{abstract}

Keywords : Temperence, Perceived Organizational Support, OCB. 


\begin{abstract}
Abstraksi
Tujuan dari penelitian ini adalah 1) mengetahui apakah temperance dan perceived organizational support dapat memprediksi organizational citizenship behavior, 2) mengetahui apakah temperance dapat memprediksi organizational citizenship behavior, dan 3) mengetahui apakah perceived organizational support dapat memprediksi organizational citizenship behavior. Metode penelitian yang digunakan adalah metode kuantitatif. Subjek dalam penelitian Guru SMA sederajat di lingkungan LP Ma'arif Kabupaten Wonosobo. Jumlah populasi penelitian 170 dengan sampel penelitian 52 Guru. Pengambilan sampel penelitian menggunakan purposive sampling. Pengumpulan data menggunakan skala temperance, skala perceived organizational support, dan skala OCB. Analisis data yang digunakan yaitu regresi berganda dengan bantuan IBM SPSS. Hasil penelitian menunjukkan 1)Temperance dan perceived organizational support dapat memprediksi organizational citizenship behavior dengan $R$ squere 0,418 , 2)Temperance dapat memprediksi organizational citizenship behavior dan 3) Perceived organizational support dapat memprediksi organizational citizenship behavior.
\end{abstract}

Kata kunci : Temperance, Perceived organizational support, $O C B$

\title{
Pendahuluan
}

Sumber daya manusia sebagai salah satu bagian dari organisasi dalam mencapai tujuan menjadi hal yang harus diperhatikan. Sumber daya manusia mempunyai peran yang sangat penting sebagai motor penggerak tercapainya tujuan organisasi.Keberhasilan organsisasi ditentukan apabila pegawai tidak hanya mengerjakan tugas pokoknya saja namun juga mau melakukan tugas ekstra seperti mau bekerja sama, tolong menolong, memberikan saran, berpartisipasi secara aktif, memberikan pelayanan ekstra kepada pengguna, serta mau menggunakan waktu kerjanya dengan efektif. ${ }^{1}$ Perilaku karyawan tersebut secara umum diistilahkan sebagai Organizational citizenship behavior, yang selanjutnya disingkat OCB.

OCB merupakan perilaku pendukung yang tidak berkaitan langsung dengan sistem reward (hadiah) untuk meningkatkan fungsi efektif organisasi. Faktor yang mempengaruhi OCB diantaranya karakteristik organisasi, karakterisktik pekerjaan, karakteristik individu, dan karakteristik

\footnotetext{
${ }^{1}$ Husniati, R. \& Pangestuti, D.C. Organizational Citizenship Behavior (Ocb) Pada Pegawai Upn "Veteran" Jakarta. Jurnal Bakti Masyarakat Indonesia 1. 1, (2018): (234-241).
}

Dirasah, Vol. 3, No.2, Agustus 2020 
kepemimpinan. ${ }^{2}$ Faktor lainnya berupa dukungan organisasi atau perceived organizaional support ${ }^{3}$ dan character strengths di tempat kerja ${ }^{4}$. Penelitian ini bertujuan untuk membuktikan kaitan antara karakter temperance dan perceived organizaional support dalam memprediksi perilaku OCB pada guru di Lembaga Pendidikan Ma'arif Kabupaten Wonosobo.

Peneliti melakukan observasi dan wawancara awal sebagai data preliminary penelitian di beberapa sekolah tingkat atas Lembaga Pendidikan Ma'arif selama enam hari, yaitu pada tanggal 16 hingga 21 april 2019. Wawancara awal dilakukan dengan Sekertaris LP Ma'arif untuk memetakan beberapa sekolah yang diasumsikan memiliki OCB rendah dengan melihat kualitas sekolah, kinerja guru dan komitmen terhadap lembaga. Hasil wawancara menyebutkan terdapat beberapa sekolah yang diasumsikan sebagian besar guru memiliki OCB yang rendah. Asumsi peneliti tentang rendahnya perilaku OCB pada guru di bawah naungan Lembaga Pendidikan Ma'arif Kabupaten Wonosobo ditunjukan dengan perilaku altruisme yang rendah, seperti ketika ada guru yang tidak masuk tanpa menitipkan tugas kepada guru piket secara langsung, tidak ada inisiatif dari guru piket untuk menanyakan atau memberikan tugas kepada siswa sesuai dengan pemahamannya. Contoh lain, aspek conscientiousnes pada karakter temperance, yaitu di mana seorang guru atau karyawan melakukan pekerjaannya melebihi standar minimun yang diharapkan organisasi kurang begitu nampak. Hal ini diakui oleh beberapa narasumber yang mengatakan bahwa hanya melakukan pekerjaan sesuai dengan job description. Mereka baru akan melakukan perbaikan apabila diminta oleh Kepala sekolah atau atasan.

OCB menjadi hal yang menarik untuk diteliti karena menyangkut perilaku dari tiap-tiap individu di dalam organisasi. OCB merupakan perilaku pilihan yang tidak menjadi kewajiban kerja formal karyawan, tetapi dapat mendukung fungsi organisasi secara efektif. ${ }^{5}$ Dua komponen utama OCB adalah kepatuhan, yang menunjukkan niat untuk mengikuti aturan organisasi, dan altruisme yang

${ }^{2}$ Podsakoff, P.M., MacKenzie, S.B., Paine, J.B. and Bachrach, D.G, “Organizational Citizenship Behaviors: A Critical Review Of The Theoretical And Empirical Literature And Suggestions For Future Research", Journal of Management, Vol. 26 No. 3.

${ }^{3}$ Sahrah, A. (2017). Perceived Organizational Support dan Organizational Citizenship Behavior pada Perawat Rumah Sakit. Jurnal Insight 19 ISSN: 1693-2552, (2000): (40-56).

${ }^{4}$ Lavy, S. \& Ovadia, H.T. My Better Self: Using Strengths at Work and Work Productivity, Organizational Citizenship Behavior, and Satisfaction. Journal of Career Development. 4.2, (2015): (95-109).

${ }^{5}$ Robbins, S. Perilaku organisasi.( Jakarta: PT Indeks Kelompok Gramedia, 2006). 
berarti pegawai berperilaku sukarela untuk membantu orang lain dalam bekerja. OCB merupakan perilaku seseorang pegawai bukan karena tuntutan tugasnya namun lebih kepada kesukarelaannya.

Beberapa penelitian menyebutkan bahwa character strengths, dalam hal ini adalah temperance memiliki korelasi dengan perilaku OCB karyawan di tempat kerja. Penelitian yang menghubungkan karakter, produktivitas kerja, OCB, dan kepuasan kerja menunjukan bahwa perilaku $O C B$ salah satunyadipengaruhi oleh temperance. Temperance dianggap sebagai anteseden penting dari sikap dan fungsi kerja, sehingga organisasi dalam mengambil kebijakan mempertimbangkan variabel tersebut yang dimiliki karyawan. Organisasi juga perlu memberikan kesempatan kepada karyawan untuk lebih mengenali dan mengembangkannya. ${ }^{6}$

Temperance merupakan salah satu virtue dalam teori character strengths yang dikembangkan oleh Martin E.P Seligman, Park, Peterson dan Ilmuan lain, sebagai upaya mengembangkan perspektif psikologi positif. Temperancedidefinisikan sebagai "strengths protecting against excess" yaitu merujuk pada pengekspresian yang pantas dan moderat dari hasrat dan keinginan pada diri. Sebagian ditentukan oleh apa yang seseorang hindari. Orang yang memiliki temperance tidak menekan keinginan, tetapi menunggu kesempatan untuk memenuhinya sehingga tidak merugikan diri sendiri dan orang lain. Karakter ini akan membawa seseorang kepada perilaku positif dan bertanggung jawab terhadap pekerjaan, dan akan membawanya pada pencapaian yang maksimal. ${ }^{7}$

Penggunaan temperance di dalam dunia kerja dianggap sebagai hal yang penting. Temperance diasusmsikan dapat mengarahkan orang untuk melakukan hal yang benar, menjadi produktif, memberi manfaat bagi karyawan lain, dan menguntungkan bagi organisasi. ${ }^{8}$ Sebagian besar penelitian berfokus variabel tersebut sebagai anteseden terkait dengan pekerjaan yang positif, sebagai

\footnotetext{
${ }^{6}$ Peterson, C., Stephens, J.P., Park, N.,Lee, F., \& Seligman, M.E.P. Strengths of Character and Work, ( New York: Oxford University Press, 2009)

${ }^{7}$ Peterson, C. \& Seligman, Martin E.P. Character strengths and Virtue: a Handbook and Classification., ( New York: Oxford University Press, 2004).

${ }^{8}$ Peterson, C., \& Park, N. Characterstrengths in organizations. Journal of Organizational Behavior, 27,, (2006): 1149-1154.
}

Dirasah, Vol. 3, No.2, Agustus 2020 
contoh dikaitkan dengan efektifitas mengatasi masalah, kepuasan kerja, dan produktifitas kerja. $^{9}$

Faktor perilaku OCB lainya adalah Perceived organizational support, yaitu persepsi karyawan terhadap tempat kerja yang memiliki karakter yang mendukung keberadaan dan pengembangan diri karyawan secara positif melalui budaya organisasi, iklim organisasi dan reward system yang sesuai. Dukungan tersebut dapat menjadi anteseden OCB, dimana karyawan akan menunjukkan OCB sebagai bentuk timbal balik atas apa yang diberikan karyawan. Beberapa penelitian tentang hubungan dukungan organisasi terhadap OCB menunjukan bahwa dukungan organisasi atau Perceived organizational support mempengaruhi karyawan memiliki OCB yang tinggi. ${ }^{10}$

Teori perceived organizational support merupakan teori yang didasarkan pada social exchange theory, di mana hubungan antara karyawan dengan organisasi merupakan hubungan pertukaran. Penyatuan mendalam tersebut membuat karyawan merasa bertanggungjawab untuk memberikan kontribusinya bagi organisasi. ${ }^{11}$ Study tentang hubungan antara perceived organizational support dan OCB menyebutkan bahwa terdapat hubungan positif antara keduanya. Sistem kompensasi, keadilan organisasi, kepemimpinan, dan pemberdayaan sebagai bagian pembentuk perceived organizational support meningkat, berpengaruh positif terhadap perilaku OCB karyawan. ${ }^{12}$

Berdasarkan uraian permasalahan yang didukung dengan teori dan hasil penelitian terdahulu peneliti, maka hipotesis yang peneliti ajukan yaitu temperance dan perceived organizational support secara signifikan dapat memprediksi perilaku OCB pada guru di Lingkungan Pendidikan Ma'arif Kabupaten Wonosobo. Adapun kerangka pemikiran sebagai berikut:

\footnotetext{
${ }^{9}$ Lavy, S. \& Ovadia, H.T. My Better Self: Using Strengths at Work and Work Productivity, Organizational Citizenship Behavior, and Satisfaction. Journal of Career Development. 4.2 , (2015): (95-109).

${ }^{10}$ Setiawan, I.A. Hubungan Antara perceived organizational support, job engagement, dan task performance, dengan organizational citizenship behavior. Jurnal sains managemen \& akuntansi 4. 12, (2012): (1-14).

${ }^{11}$ Rhoades, L., Eisenberger, R. Perceived Organizational Support: A Review of The Literature. Journal of Applied Psychology. 87., (2002): (4).

${ }^{12}$ Danish, R.Q \& Humayon.. Relationship Between Perceived Organizational Support and Organizational Citizenship Behavior; a Study of Employees in National Highway Authority of Pakistan. American Journal of Economics, Finance and Management. 1. 3, 2015, (2015): (195-199).
} 


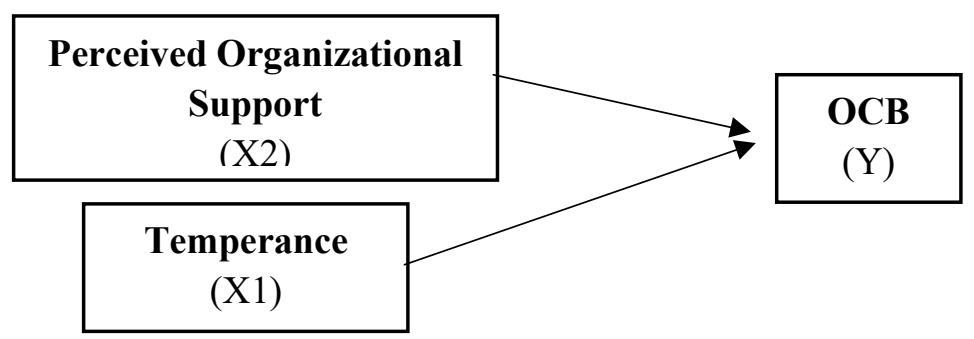

Gambar 1. Kerangka Pemikiran

Sumber: Hasil Olahan Penulis, 2019

\section{Metode}

Penelitian ini menggunakan metode kuantitatif korelasional. Variabel bebas yaitu temperance yang dikemukakan oleh Peterson dan Seligman $(2004)^{13}$ dan perceived organizational support dari Rhoades dan Eisenberger (2002).${ }^{14}$ Variabel tergantung adalah OCB yang digagas Organ, dkk (2006). ${ }^{15}$

Populasi dalam penelitian ini adalah guru tingkat SMA di lingkungan Lembaga Pendidikan Ma'arif Kabupaten Wonosobo dengan Jumlah 175 guru yang terbagi dalam delapan sekolah. Teknik pengambilan sampel dalam penelitian ini menggunakan Purposive sampling, yaitu peneliti menentukan pengambilan sampel dengan cara menetapkan ciri-ciri khusus yang sesuai dengan tujuan penelitian.

Metode yang digunakan dalam pengumpulan data pada penelitian ini menggunakan skala. Skala OCB disusun oleh Tentama berdasarkan aspek OCB yaitu: Altruism,Sportmanship, Conscientiousness, Courtesydan CivicVirtue. Skala temperence berupa skala yang disusun peneliti dengan mengacu pada aspek-aspek temperence yaitu meliputi 4 aspek yaitu forgiveness, modesty, prudence, dan self-regulation. Skala Perceived organizational support berupa skala yang diadaptasi dari Aulia yang disusun dengan mengacu pada tiga aspek Perceived organizational support dengan aspek Fairness, supervisory support, organizational reward \& job conditions.

\footnotetext{
${ }^{13}$ Peterson, C. \& Seligman, M.E.P. Character strengths and Virtue: a Handbook and Classification., ( New York: Oxford University Press, 2004).

${ }^{14}$ Rhoades, L., Eisenberger, R. Perceived Organizational Support: A Review of The Literature. Journal of Applied Psychology. 87,(2002): (4).

${ }^{15}$ Organ, D. W., Podsakoff, P. M \& MacKenzie, S. B. Organizational citizenship behavior: Its nature, antecedents, and consequences, (USA: Sage Publications, 2006).
}

Dirasah, Vol. 3, No.2, Agustus 2020 
Teknik analisis yang digunakan untuk menganalisa data yang diperoleh dalam penelitian ini adalah dengan teknik Analisis Regresi Berganda. Proses analisis data dilakukan dengan program komputerisasi IBM SPSS. Metode pengumpulan data menggunkan skala melalui uji validitas, seleksi item, reliabilitas. Selanjutnya asumsi yang harus dipenuhi untuk melakukan analisis data adalah uji normalitas, uji linieritas, serta uji hipotesis.

\section{Hasil dan Pembahasan}

Uji Validitas menggunakan validitas isi dan reliabilitas yang dilakukan menggunakan formula Alpha Cronbach. Adapun hasil uji coba skala penelitian adalah sebagai berikut:

1. Instrument skala $\mathrm{OCB}$ dari 20 item nilai corrected item-total correlation yang di bawah 0,3 terdapat 3 item yang gugur. Kemudian peneliti melakukan penyelarasan dan didapatkan 15 item yang dianggap valid dan memenuhi reliabilitas dengan nilai Cronbach's Alpha sebesar 0.907.

2. Pada skala temperance jumlah item yang diuji coba sebnayk 32, setelah dilakukan analisis dan penyetaraan peneliti mengasilkan 12 item yang dianggap valid dan reliabel dengan nilai koefisien reliabilitas skala Temperence sebesar 0,886 .

Skala perceived organizational support sebanyak 12 item, setelah dilakukan uji coba dan analisis tidak terdapat item yang gugur. Maka peneliti menggunakan semua item karena dianggap valid dan reliabel dengan dengan nilai koefisien reliabilitas sebesar 0,925 .

Sebelum dilakukan uji hipotesis, terlebih dahulu dilakukan uji asumsi terhadap data yang telah dikumpulkan. Uji asumsi yang digunakan yaitu uji normalitas, uji linieritas, dan uji multikolinieritas.

a. Uji Normalitas

Pengujian normalitas menggunakan teknik statistik one sample Kolmogorov-Smirnov Test (KS-Z) dari program IBM Statistics.

Hasil uji normalitas sebagai berikut:

\section{Tabel 1. Uji Normalitas}

\begin{tabular}{cccl}
\hline Variabel & K S-Z & Sig $(\mathbf{p})$ & Keterangan \\
\hline $\mathrm{X} 1$ & 0,118 & $0,150(\mathrm{p}>0,05)$ & Terdistribusi Normal \\
\hline $\mathrm{X} 2$ & 0,114 & $0,86(\mathrm{p}>0,05)$ & Terdistribusi Normal \\
\hline $\mathrm{Y}$ & 0,111 & $0,86(\mathrm{p}>0,05)$ & Terdistribusi Normal \\
\hline
\end{tabular}


Berdasarkan hasil uji normalitas tabel diatas diketahui sebaranmenunjukan ketiga variabel berdistribusi normal.

b. Uji Linieritas

Hasil uji linieritas antaratemperance dengan OCBmenunjukkan nilai taraf signifikan $p=0,791(p>0,05)$, yang berarti ada hubungan yang linier atau membentuk garis lurus antaratemperance dengan OCB.Hasil uji linieritas antara perceived organizational support dengan OCB menunjukkan taraf signifikan $\mathrm{p}=0,993(\mathrm{p}>0,05)$, yang berarti ada hubungan yang linier atau membentuk garis lurus antaraperceived organizational support dengan OCB.

c. Uji Multikolinieritas

Uji multikolinearitas diperoleh data nilai Tolerance $(0,788>0,1)$ dan VIF $(1,268<10)$ kedua variabel bebas terhadap variabel terikat dapat diterima, sehingga dapat disimpulkan tidak terjadi multikolinearitas atau tumpang tindih antar variabel bebas dengan variabel terikat.

d. Uji Hipotesis

Setelah dilakukan uji asumsi, peneliti melakukan uji hipotesis dengan hasil sebagai berikut:

Tabel 2. Hipotesis mayor

\begin{tabular}{lccc}
\hline \multicolumn{1}{c}{ Variabel } & R & R square & Sig \\
\hline $\begin{array}{l}\text { Temperance dan perceived } \\
\text { organizational support } * \text { OCB }\end{array}$ & .646 & .418 & 0,000 \\
& & & \\
\hline
\end{tabular}

Berdasarkan tabel di atas dapat diketahui nilai koefisien korelasi $\mathrm{R}$ sebesar 0,646 dengan taraf signifikan $p=0,000(p<0,05)$, artinya terdapat hubungan yang sangat signifikan antara temperance dan perceived organizational support dengan OCB pada guru di LP Ma'arif, dengan demikian hipotesis mayor diterima. Selain itu diketahui nilai $\mathrm{R}$ square sebesar 0,418 artinya CS dan POS memberikan sumbangan efektif sebesar $41,8 \%$ terhadap OCB.

Peneliti kembali melakukan uji hipotesis minor untuk melihat lebih lanjut hubungan antara variabel bebas dengan variabel terikat. hasil uji koefisien regresi antara variabel teperance dengan variabel OCB nilai yang diperoleh $\mathrm{B}=0,434$ dengan taraf signifikan $\mathrm{p}=0,002(\mathrm{p}<0,05)$, artinya terdapat hubungan yang signifikan dan positif antara temperance dengan 
OCB, dengan demikian hipotesis minor pertama diterima. Hasil uji koefisien regresi antara variabel perceived organizational support dengan variabel OCB nilai yang diperoleh $\mathrm{B}=0,294$ dengan taraf signifikan $\mathrm{p}=$ $0,006(\mathrm{p}<0,05)$, artinya terdapat hubungan yang signifikan dan positif antara perceived organizational support dengan OCB. Dengan demikian hipotesis minor kedua diterima.

a. Analisis lanjutan

\section{Tabel 3. Sumbangan Efektif}

\begin{tabular}{lc}
\hline \multicolumn{1}{c}{ Variabel } & Sumbangan Efektif \\
\hline Teperance * OCB & $22,76 \%$ \\
\hline perceived organizational support $*$ OCB & $19,04 \%$ \\
\hline
\end{tabular}

R Square

Hasil analisis sumbangan efektif variabel temperance terhadap OCB sebesar 22,76\% dan sumbangan efektif variabel Perceived Organizational Support terhadap OCB sebesar 19,4\%. Artinya sumbangan variabel temperance lebih dominan dari pada sumbangan variabel Perceived Organizational Support terhadap OCB pada guru di Lembaga Pendidikan Ma'arif kabupaten wonosobo.

Hasil analisis menyebutkan bahwa Temperance dan Perceived Organizational Support secara signifikan dapat memprediksi OCB pada guru di Lembaga Pendidikan Ma'arif Kabupaten Wonosobo. Dengan kata lain bahwa OCB guru akan meningkat jika memiliki karakter temperence dan perceived organizational support yang tinggi.

Hasil yang membuktikan bahwa temperence sebagai salah satu variabel yang mampu memprediksi perilaku OCB dikuatkan oleh pendapat Peterson dan seligman (2004) bahwa temperance baik yang kuat dalam diri akan membawanya kepada perilaku positif dan bertanggung jawab terhadap pekerjaan, dan akan membawanya pada pencapaian yang maksimal. ${ }^{16}$ Temperance dalam diri berkorelasi positif dengan perilaku OCB, produktifitas kerja, dan kepuasan kerja. ${ }^{17}$

Keterkaitan antara temperance dengan perilaku OCB dapat dijabarkan dengan melihat aspek-aspeknya. Pertama, forgiveness membuat seseorang dapat memaafkan orang lain yang berbuat salah, memberi orang lain kesempatan kedua. Modesty adalah pribadi yang rendah hati tidak

\footnotetext{
${ }^{16}$ Peterson, C. Character strengths and Virtue.

${ }^{17}$ Lavy, S. My Better Self..
} 
menganggap diri istimewa, tidak pretensius, dan tidak ingin orang lain mengakui serta menghargai kebersahajaan dirinya. Prudence yaitu kehatihatian, tidak mengatakan atau melakukan hal-hal yang dikemudian hari mungkin disesali, dan self regulation yaitu dengan mudah menahan nafsu, keinginan, dorongan pada saat yang tepat,dan mampu mewujudkan pengetahuan tadi menjadi aksi. Keempat aspek tersebut sangat penting dalam pekerjaan, baik dalam menyelesaikan tugas-tugas maupun pola hubungan dengan pekerja lain.

Perceived organizational support menjadi variabel lain dalam penelitian ini yang secara signifikan mampu memprediksi perilaku OCB. Hasil ini selaras dengan penelitian yang menyebutkan bahwa perceived organizational support secara signifikan berhubungan dengan perilaku OCB. ${ }^{18}$ Penelitian lain menyatakan bahwa Perceived organizational support mempengaruhi karyawan memiliki OCB yang tinggi. Kondisi lingkungan pekerjaan yang positif sebagai bentuk dukungan organisasi berkorelasi positif terhadap perilaku OCB. ${ }^{19}$

\section{Penutup}

Berdasarkan hasil analisis data dan pembahasan, maka dapat diambil kesimpulan yaitutemperence dan perceived organizational support mampu memprediksi perilaku OCB pada guru tingkat menengah atas di lingkungan LP Ma'arif kabupaten Wonosobo.Temperance memiliki sumbangan lebih besar terhadap perilaku OCB dari pada perceived organizational support.

\footnotetext{
${ }^{18}$ Podsakoff, "Organizational Citizenship Behaviors.

${ }^{19}$ Putra, D.S. Hubungan Antara Perceived Organizational Support Dengan Organizational Citizenship Behavior Pada Karyawan Pt En Seval Putera Megatrading Divisi Transportasi Cabang Sidoarjo. Jurnal Psikologi Industri dan Organisasi. 2. 1, (2013): (61-75).
}

Dirasah, Vol. 3, No.2, Agustus 2020 


\section{Daftar Pustaka}

Danish, R.Q \& Humayon. Relationship Between Perceived Organizational Support and Organizational Citizenship Behavior; a Study of Employees in National Highway Authority of Pakistan. American Journal of Economics, Finance and Management. 1. 3, 2015, (2015): 195-199.

Husniati, R. \& Pangestuti, D.C. Organizational Citizenship Behavior (Ocb) Pada Pegawai Upn "Veteran" Jakarta. Jurnal Bakti Masyarakat Indonesia 1. 1, (2018): 234-241.

Lavy, S. \& Ovadia, H.T. My Better Self: Using Strengths at Work and Work Productivity, Organizational Citizenship Behavior, and Satisfaction. Journal of Career Development. 4.2 , (2015): 95-109.

Organ, D. W., Podsakoff, P. M \& MacKenzie, S. B . Organizational citizenship behavior: Its nature, antecedents, and consequences. USA: Sage Publications, 2006.

Peterson, C. \& Seligman, Martin E.P. Character strengths and Virtue: a Handbook and Classification. New York: Oxford University Press, 2004.

Peterson, C., \& Park, N. Characterstrengths in organizations. Journal of Organizational Behavior, 27,(2006): 1149-1154.

Peterson, C., Stephens, J.P., Park, N.,Lee, F., \& Seligman, M.E.P. Strengths of Character and Work. New York: Oxford University Press, 2009.

Podsakoff, P.M., MacKenzie, S.B., Paine, J.B. and Bachrach, D.G, "Organizational Citizenship Behaviors: A Critical Review Of The Theoretical And Empirical Literature And Suggestions For Future Research", Journal of Management, Vol. 26 No. 3, 2000.

Putra, D.S. Hubungan Antara Perceived Organizational Support Dengan Organizational Citizenship Behavior Pada Karyawan Pt En Seval Putera Megatrading Divisi Transportasi Cabang Sidoarjo. Jurnal Psikologi Industri dan Organisasi. 2. 1., (2013):61-75.

Rhoades, L., Eisenberger, R. Perceived Organizational Support: A Review of The Literature. Journal of Applied Psychology. 87, (2002): 4. 
Robbins, S. Perilaku organisasi. Jakarta: PT Indeks Kelompok Gramedia, 2006.

Sahrah, A. Perceived Organizational Support dan Organizational Citizenship Behavior pada Perawat Rumah Sakit. Jurnal Insight 19 ISSN: 1693-2552, (2017) : 40-56.

Setiawan, I.A. Hubungan Antara perceived organizational support, job engagement, dan task performance, dengan organizational citizenship behavior. Jurnal sains managemen \& akuntansi 4. 12., (2012): 1-14.

Copyright (C) 2020Journal Dirasah: Vol. 3, No.2, Agustus 2020, p-ISSN: 2615-0212, e-ISSN; 2621-2838

Copyright rests with the authors

Copyright of Jurnal Dirasah is the property of Jurnal Dirasah and its content may not be copied oremailed to multiple sites or posted to a listserv without the copyright holder's express writtenpermission. However, users may print, download, or email articles for individual use. https://ejournal.iaifa.ac.id/index.php/dirasah 